\title{
Failure to Transmit Record
}

National Cancer Institute

\section{Source}

National Cancer Institute. Failure to Transmit Record. NCI Thesaurus. Code C63155.

Problem associated with a failure of the device to transmit a record for interpretation or measurement. 